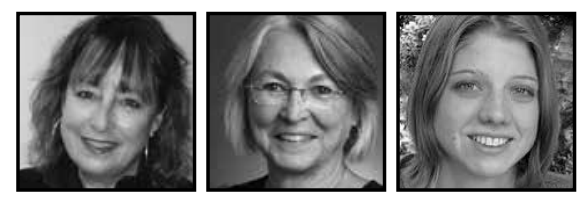

\title{
Culturally Responsive Teaching: Stories of a First Nation, Métis, and Inuit Cross-Curricular Infusion in Teacher Education
}

\author{
Diane Vetter, Celia Haig-Brown, and Melissa Blimkie, York University
}

\begin{abstract}
This paper explores how the work of the infusion of First Nation, Métis, and Inuit traditions, perspectives, and histories at York University's Faculty of Education Barrie Site unfolds in practice. It also highlights the learning experiences of pre-service teachers, the majority of whom were non-Aboriginal. Using narrative accounts of practice in faculty and practicum classrooms, the authors elaborate on a set of guiding principles to highlight their practical application by demonstrating what their implementation looks like in local school classrooms. They subsequently describe the challenges faced by faculty and pre-service teachers as they moved theoretical knowledge into practical settings.
\end{abstract}

n 2008, the TeacherEducation Program at York University's Barrie Site began the First Nation, Métis, and Inuit Infusion (i.e., the Infusion) (See Vetter \& Blimkie, 2011). The objective of the Infusion was, and continues to be, to develop teacher candidates' knowledge of Indigenous histories, cultures, perspectives, and contemporary issues to respond to the specific needs and interests of Indigenous students, and therefore facilitate respectful and relevant learning for all students in Ontario classrooms.

The specific objectives of the Infusion at the Barrie Site include:

- placing land, Indigenous peoples, and relationships, in all their complexities of languages and cultures, central to the development of sound and caring teaching practices; 
- excising deficit theorizing from our hearts and minds; and

- examining critically what it means to take seriously Indigenous peoples, lands, and perspectives in development of culturally responsive pedagogies in Ontario schools (Haig-Brown, 2008).

Through analysis of teacher candidates' responses shared in focus groups and questionnaires of our exploratory case study, we articulated a set of guiding principles for teaching Aboriginal content in culturally respectful and meaningful ways (Blimkie, Vetter, \& Haig-Brown, 2014). The principles are:

1. Understand that "not knowing" is an opportunity for learning

2. Recognize diversity of histories and teachings

3. Create space for alternate perspectives

4. Teach in context, using resources responsibly

5. Move from inclusion to infusion

In this paper, we will expand upon each of these principles to highlight their practical application and demonstrate what the implementation looks like in local school classrooms. We will also describe the challenges faced by faculty and pre-service teachers as they moved theoretical knowledge into practical settings. Our work uses narrative inquiry (Bruner, 2003) and the power of story (King, 2003) to make meaning of the experiences of the Infusion.

\section{Understand That "Not Knowing" Is an Opportunity for Learning}

Embracing this first principle was a big leap for teacher candidates. In our classroom they expressed their concerns about lacking the confidence to work within a context that was outside of their comfort zone in terms of knowledge and understanding. Despite studying foundational education theorists (e.g., Bruner, 1966; Freire, 1974; Wells \& Chang-Wells, 1992) whose work emphasized that educators could no longer be seen as expert repositories of knowledge to be transmitted to students, our teacher candidates remained reluctant to admit "not knowing" (Blimkie et al., 2014) to their students and mentor teachers. Consequently, as Dion (2007) has pointed out, some used movement to the position of "perfect stranger" as justification for avoiding Aboriginal content and pedagogies in their classes. 
At the Barrie Site, we addressed this issue by replacing a required Models of Education course with a course entitled, "Issues in Indigenous Education." While this step worked to assuage some of the fears held by our teacher candidates, we realized that the enormity of the content could barely be touched by a 36-hour course. If we were to expect our teacher candidates to take the Infusion concept into local classrooms, we needed a strategy that supported them in their daily practice. Therefore, we modeled the process of engaging in "collaborative meaning making" (Wells \& Chang-Wells, 1992) to support teacher candidates in understanding that learning with students is a valuable exercise, and that infusing First Nation, Métis, and Inuit traditions, perspectives, and histories could be undertaken by holding true to the following three objectives:

1. Demonstrating respect for First Nation, Métis, and Inuit traditions, perspectives, and histories

2. Taking responsibility for increasing their personal understanding and learning collaboratively with their students

3. Facilitating meaningful learning through relationship-building with First Nation, Métis, and Inuit peoples and organizations in the region

\section{Demonstrating Respect for First Nation, Métis, and Inuit Traditions, Perspectives, and Histories}

Our objective of demonstrating respect sounded quite straightforward; however, moving the Infusion into local schools challenged our teacher candidates when respect, coupled with genuine enthusiasm, verged on appropriation of stories or traditions over which they held no cultural authority. Therefore, thoughtful consideration of what both teacher candidates and faculty brought to their respective classrooms and how we all did so necessarily permeated every action. The following is one example of how we attempted to demonstrate respect for tradition:

We were fortunate to have the support of local First Nation, Métis, and Inuit community members who shared their knowledge and guided our work. We had learned about the tradition of giving a gift of tobacco. So, prior to the visit of a local Elder to our classroom we would discuss this tradition and the fine line between demonstrating respect and appropriating tradition. In one class, we had a teacher candidate who had always lived in a rural setting close to a First Nation community. As a way of life, he had always honoured and respected their traditions. As a farmer, he also grew his own crops, including tobacco. He offered to prepare a tie of tobacco from his farm for our visiting Elder. The teacher candidates agreed that this was a fitting gift, due to the personal history and understandings of the tradition that our teacher candidate held. 
Another year, no member of the class had that same understanding and the teacher candidates were concerned about how they might honour the tradition without feeling they had appropriated something that was not their own. After much discussion, they decided to choose a book as a gift for the Elder. In presenting the gift, it was explained that the book represented knowledge and was given to honour the sharing of knowledge that the Elder had brought to the class.

The decision to give a gift other than tobacco stemmed from a lack of full understanding of the cultural protocol, a fear of crossing the line between showing respect and appropriating traditions without cultural authority, and a hesitancy to ask directly. The following statement from one of the course directors explains further:

During the first year of the Infusion at the Barrie site (2008-2009) I received a teaching on tobacco from which I inferred that, as someone who had a very introductory knowledge of tobacco, I needed to be careful about using it to thank First Nation people, especially people whol did not know. While visiting the six teacher candidates at their First Nation placements in Garden River and Sault Ste. Marie, we were invited to a drumming circle at the home of one of our First Nation partners. Before the drumming circle, one teacher candidate asked me if we should give tobacco, as she was unsure if it was culturally appropriate. I acknowledged that I was also uncertain and shared my interpretation of the teaching on tobacco that I had received the previous year, but I told her that it was her decision to make. She decided not to give tobacco because she did not know the teachings of tobacco. At the drumming circle, we asked our First Nation partner about giving tobacco, and his response was that we did not have to give tobacco, but "it would have been nice." I felt awful. Not only did we not give tobacco, but my words most likely deterred the teacher candidates from doing so. As one of our partners said, "You were thinking with your mind rather than your heart." Rather than taking the time to feel the atmosphere at the drumming circle, I generalized my limited knowledge on tobacco to all situations. From this experience, we learned about respecting cultural protocol, which may be different depending on the community as well as the person. We began to see the insincerity of broad generalizations and we learned the importance of asking our First Nation partners if they would like to be given tobacco when they share their knowledge and experience with us. (M. Blimkie, personal communication, May 26, 2010)

The extrapolation of the tobacco learning experience began to appear in the work of our teacher candidates in their host classrooms. For example, one teacher candidate read her class a story from a published text about dream catchers (Meuse-Dallien, 
2003); however, understanding the sacred significance of the dream catcher, she did not turn it into the classroom craft-making activity that it might have easily become.

The discussion of cultural appropriation and authority led to the consideration of normalization, and the impact of Aboriginal culture on ways that we may now consider to be simply Canadian. Saul's (2009), A Fair Country: Telling Truths About Canada, became a required course text and subject of critical analysis. As an example of how this conversation moved into schools, our teacher candidates recognized that the concept of the circle has for many years been normalized in a number of classrooms, particularly in the primary divisions. In their host classrooms, teacher candidates respected Indigenous ways of knowing by acknowledging the history of the Talking Circle, so that children might be aware of its origins and the significance of the circle to Indigenous peoples (Simcoe Catholic District School Board, 2008).

To undertake work of the Infusion by demonstrating respect, we need to continue learning about cultural protocols, develop further understandings about the importance of cultural authority, and remember to ask for clarification when we are unsure.

\section{Taking Responsibility for Increasing Their Personal Understanding and Learning Collaboratively With Their Students}

In taking responsibility for personal learning, and that of the students in our faculty and in the schools where they undertake practicum, we relied on the following quotation from Kulchyski (2005) to give emphasis to this understanding:

In the minutiae of quotidian life, in the presuppositions of service providers, in the structures of State actions and inactions, in the continuing struggles over land use, in the whole trajectory of policies and plans, the work of the conquest is being completed here and now. By our generation...You who remain silent while this injustice continues, you are responsible. Here. And now. (p. 3)

While a small minority of teacher candidates remained resistant to the notion, most engaged readily in taking responsibility for self-evaluating and expanding their knowledge (Blimkie et al., 2014).

In conversation with teacher candidates, we realized that two major gaps existed in their understandings. The first gap represented the issues that had been omitted from their prior education, such as the existence and intergenerational impact of residential schooling. The second gap encompassed what they thought they knew and how that 
knowing was often misconstrued by misconceptions and stereotypical beliefs. One teacher candidate stated:

I remember feeling surprised and shocked that I didn't know as much as I thought I did. I think part of it was because I've been educated in the area of whoever's agenda it is... g guess you think that Canada is a free country. That everyone is so happy and we don't really have any dirt, but there's a ton of dirt here that we don't talk about it. (June 2010 Focus Group 2, Participant 2)

With an intent to address the gaps of understanding and misunderstanding, challenge thinking, and provide a space for teacher candidates to become agents of change, we made compulsory an Issues in Indigenous Education course that had the following objectives:

1. Explore the ongoing impact of colonization

2. Promote decolonizing approaches by challenging deficit thinking

3. Present successful educational models with the possibility of practitioners integrating aspects of these methods into personal practice

The course also facilitated independent research on topics of specific interest to teacher candidates that were subsequently presented to the class in order to share the understandings. The evaluation followed a circle framework (Blimkie, Vetter, \& Stewart, 2011; McGregor, 2008/2010), and encompassed learning from spirit, heart, mind, and body. In this framework, students were assessed relative to their learning goals with the format open to multiple means of representation, including oral, dance, multimedia, text, music, art, and drama.

In the primary host classrooms, the sharing of independent research that was undertaken in the faculty classroom morphed into a "Knowing Basket," which is a large basket where children could contribute hand-written texts, drawings, names of favourite books, or weblinks, and so forth. A popular free-time activity in some host classrooms became going to the Knowing Basket and exploring something new. The content of the basket reflected a wide array of topics and interests, many of which became increasingly related to First Nation, Métis, and Inuit traditions and culture as children in the classroom emulated the teacher candidate's respect and interest.

In taking responsibility for their own learning about First Nation, Métis, and Inuit traditions and culture, our teacher candidates expanded their personal understandings and were able to model this form of learning in their host classrooms. 


\section{Facilitating Meaningful Learning Through Relationship-Building With First Nation Métis and Inuit Peoples and Organizations in the Region}

The greatest factor in the implementation of the Infusion in both the faculty and elementary school classrooms was the support of First Nation, Métis, and Inuit communities across Canada who walked with us on this journey. Without their wisdom, knowledge, and guidance our work would not have been possible.

In particular, we took encouragement from the work of the Simcoe Muskoka Catholic District School Board (2009), who undertook a comprehensive survey of local First Nation and Métis community members regarding education. Consultation participants suggested that schools "draw on role-models and Elders to pass on their knowledge - help students recognize how much knowledge they carry and find ways for them to share so they can learn from each other" (p. 35). It was noted that "teachers need to feel comfortable to call on community members, Elders, etc. and given help with identifying community resources as needed" (p. 54). One participant offered, "Just ask us; we're glad to help" (p. 55). Another concluded, "This is too important not to get it right" (p. 29). In local classrooms, our teacher candidates took these messages to heart and began inviting guests to their classrooms.

Understanding that not knowing is an opportunity for learning as a guiding principle raised challenges in practice that required a focused response by both faculty and teacher candidates. Our three objectives of demonstrating respect, taking responsibility for learning and facilitating meaningful learning through relationship-building allowed faculty and students to comfortably embrace not knowing in the work of the Infusion.

\section{Recognize Diversity of Histories and Teachings}

Every teacher candidate in the Barrie Site program had the opportunity to participate in a First Nation, Métis, or Inuit placement experience toward the end of the academic year. Teacher candidates accepted opportunities in Friendship Centres and community organizations, local public or Catholic schools with high populations of students who self-identified as First Nation, Métis, or Inuit, and in schools located within communities outside of our area. Teacher candidates travelled to placements in northern Ontario, and as far away as British Columbia and Nunavut.

Returning from these placements, teacher candidates recognized the diversity of communities, settings (rural, urban, and remote), histories, traditions, teachings, 
perspectives, and experiences. They also learned that the understandings they had of learning and schooling did not apply to all settings.

One group of teacher candidates who travelled to Nunavut noted many differences from their experiences in their local schools. For example, the mode of transportation (two hours in a qamutik-a traditional Inuit sled pulled by a snowmobile) on a kindergarten field trip to go ice fishing. These differences were somewhat expected. Therefore, teacher candidates had inquired in advance and their Inuit hosts explained how they would travel. Hosts also offered a loan of appropriate clothing as protection from the cold as they travelled at high speed over the ice in the open sleds. The most unexpected and striking difference resulted from what teacher candidates had simply presumed.

The teacher candidates had packed lunches to take with them as they would on a field trip in their local school. As lunch approached, they saw their hosts giving lunch to the children and proceeded to open their own brown bags and eat their sandwiches. It was quickly apparent that this had drawn the attention of parents and teachers. Not quite sure what to do, they slipped their sandwiches back into their bags and asked the woman who was serving lunch to the children what the concern might be. She indicated that the act of bringing a personal lunch had signalled uncertainty on the part of teacher candidates that their hosts would care for them on the trip. Their Inuit hosts were surprised and somewhat offended. The misunderstanding was soon cleared up and the teacher candidates enjoyed a wonderful Arctic char soup prepared from the day's catch. Indeed, the community looked after each other. In fact that evening the local short-wave radiobroadcast announced the great catch of the day and invited anyone in the town to come and pick up some fresh fish.

Similarly, the teacher candidates noticed that students in the Inuit school never came to school with a piece of fruit (which is an expensive commodity in the far North) without cutting it into as many pieces as there were children and teachers in the classroom to ensure everyone had a share. These teacher candidates noted that they were returning to their local schools with a new perspective on local school policy of students not sharing food from their lunches and how a child arriving from an Inuit school might perceive restrictions on sharing.

All teacher candidates remarked on the perspectives they gained from their First Nation, Métis, or Inuit placement experiences. They realized that students who travelled distances by ferry in summer or scoot in winter were not disinterested; rather, they were unable to participate in after-school activities due to ferry/scoot 
schedules. They gained a glimmer of understanding into why parents experiencing the intergenerational effects of residential schooling might choose to disengage from the school or choose not to have their child self-identify-and so attempted to provide more effective home/school communication. They stressed the importance of "being sensitive to student histories and experiences and ensuring that you do not sound like the expert on another person's life" (May 2010 Questionnaire, Participant 5).

Articulated as a guiding principle, recognizing the diversity of histories and teachings highlighted the importance of not generalizing the experiences and teachings of one Aboriginal community. In turn, it led teacher candidates to demonstrate their understanding that diversity exists within and between Aboriginal peoples and communities.

\section{Create Space for Alternate Perspectives}

Teacher candidates made a conscious effort to create spaces for perspectives that are often overlooked, ignored, or hidden. In the Inuit community, they appreciated the frankness of a school principal who articulated the challenge to the community of having a never-ending parade of well-meaning "outsiders" visit the community to teach-yet none who were ever inclined to return and very few who even kept in touch. She aptly labelled this "outsider fatigue." This was an eye-opening comment for eager teacher candidates who saw themselves as contributing to the school during their placement, but had not considered the perspective of the community.

In their local schools, teacher candidates came to realize the importance of children seeing themselves mirrored in the classroom environment rather than separated from it by an invisible window (Style, 1996) that allowed them to see in, but not fully participate. Rather than create an environment for their students, our teacher candidates came to value the importance of allowing the students to create a classroom environment that reflected the ways of knowing and being in the world of every student in the room. Teacher candidates considered whether the existing environment mirrored the faces, realities, and experiences of their students, or had created barriers. They then worked to facilitate student-created spaces, bulletin boards, and reading baskets that were respectful and reflective of the children in that classroom. 
One of our teacher candidates submitted a wooden chair as a representation of what he had come to understand about creating a culturally respectful learning environment for children. He explained his thinking as follows:

When we walk into a classroom we could name countless items that may be considered essential learning tools. One of the most basic yet essential tools for learning would be the chairs that our students sit on. Without one, our students could not work comfortably. From all that I have seen this semester I have come to one major conclusion. First Nations, Métis and Inuit (FNMI) youth are trying to obtain an education while sitting on a three-legged chair. The odds of FNMI students being successful are not very promising. The lack of success is in large part because they are being forced to learn within a system that makes very little effort to include effective practices for Indigenous education. If educators wish to break this cycle we need to focus our attention on the connection between the spiritual (black), mental (white), physical (yellow) and emotional (red) realms that are key to FNMI culture. Success will also require changes to our pedagogy so that it includes FNMI culture, language and worldviews. The healing process is going to be slow but does not mean we should not try for that is what society has done for the last 400 years (Stevens, 2009).

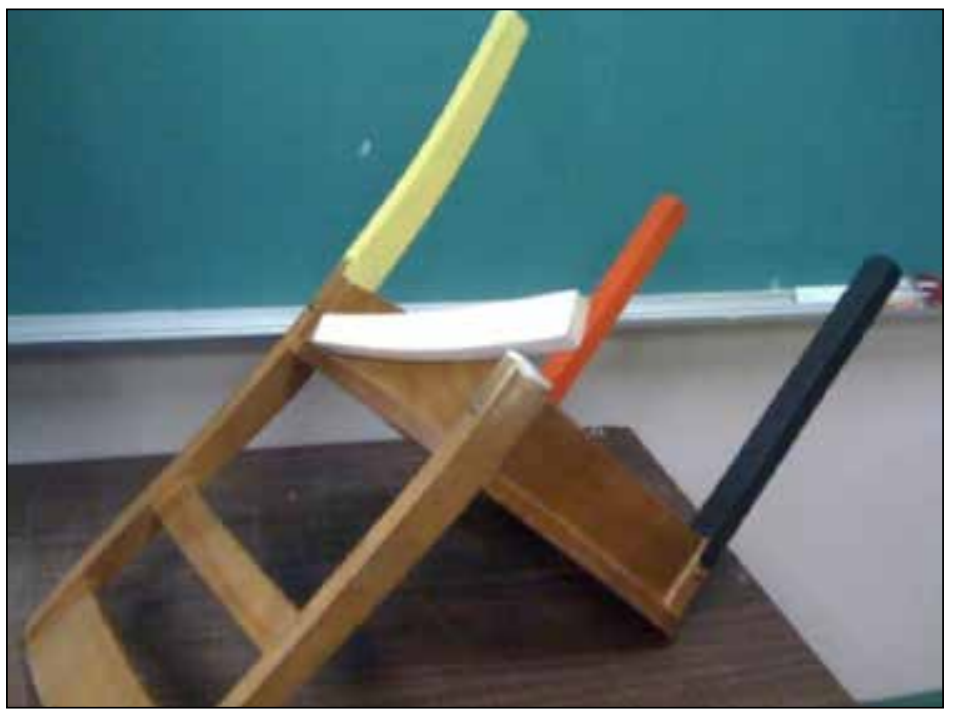

Fig. 1: Wooden chair representing culturally respectful learning 
In their local schools, teacher candidates began to consider alternative perspectives in both environment and learning. For example, a group of teacher candidates noted a mural in a local school foyer that depicted a historical event from a clearly nonAboriginal perspective. They noted that the portrayal of the Aboriginal people in the mural was, to their eyes, disrespectful. They wondered how the First Nation children in that school felt, even subconsciously, about the painting. Did they see it as an insult or were they inured to the portrayal? The teacher candidates brought their concern to our faculty classroom and we engaged with a respected member of a First Nation community who guided us as we presented the concern to the school. The positive outcome of the teacher candidates' understanding of perspective resulted in the mural being changed.

Creating space for alternate perspectives framed as a guiding principle opened up understandings of multiple ways of knowing and being in the world, which led teacher candidates to look critically at their environments and to take responsibility for helping students in their host classrooms to do the same.

\section{Teach in Context, Using Resources Responsibly}

In contrast to their prior personal education experience of focusing solely on Aboriginal history without context, teacher candidates sought ways to underscore the relevance of the history by making connections between current issues and past events. As learners who, in many cases, recognized having been schooled without this context, they understood how that lack had contributed to their lack of understanding of the relevance of the history to their present existence, and how it made it easy for them to turn away from the ugly truths of the history of colonial relationships in Canada.

The greatest challenge for teaching in context relates to our prior discussion of knowledge and cultural authority. Teacher candidates articulated a desperate need for resources they could use in a responsible manner to ensure that the information embraced multiple perspectives. They valued using teaching materials and resources developed by or, at least, in consultation with Aboriginal peoples. Seeking out and assessing resources became a topic of much discussion in our classes as teacher candidates listened for the voices in the resources and looked critically at whose perspective was presented and how. They learned how to read through the lens of "other" and to encourage even their youngest students to do likewise. 
As an example of this learning, our teacher candidates began to make use of a resource provided by the Elementary Teachers' Federation of Ontario (1999) to check a book for bias. Imagine the surprise when a guest in our classroom drew their attention to a perennial Grade 3 favourite, Little House on the Prairie (Wilder, 1935/1994), where they read the following dialogue of the character of Mr. Scott, "The only good Indian is a dead Indian" (p. 284). Their awareness of perspective had provided them with a new lens, which they then shared with their young students. Many also implemented an idea shared by one of our First Nation partners to glue a library pocket into the back of books, so students could insert small cards containing their commentary on evidence of racism or bias in that text. This simple practice empowered young readers who could look at the commentary to inform their reading choices and drive them to ask whose perspective was presented in a given text.

Many teacher candidates emphasized that "Aboriginal students should not be used as the 'go to' expert" (May 2010 Questionnaire, Participant 33). They understood the unfairness of presuming a child to be an expert, and sought support from Elders or other knowledgeable partners. They also came to understand that while they might share understandings, there was a distinct difference between sharing histories from respected sources and teachings or storytelling that held sacred meaning, which required ceremony or ritual and cultural authority.

It would be naïve to presume that these learnings came to us (teacher candidates and faculty) intuitively. Certainly there were those that came to us harshly and reminded us that there will be no point of arrival, simply an ongoing path of learning. One such example was a recommendation for a guest speaker in our faculty classroom. The speaker had published on a topic of interest and was recommended to us as an engaging speaker. Not long into the speaker's presentation, it became apparent to us that the non-Aboriginal speaker's jocular style of delivery demonstrated a lack of respect for important content and the storytelling was void of the cultural authority, which the speaker had previously intimated. After some squirming in our seats, the group began to challenge the speaker. The presentation ended not long after with much relief, no doubt, on both sides. We learned to examine our perspective, asking ourselves-prior to extending an invitation-how we might have looked beyond the prestige of publishing to the authenticity and cultural authority of our speaker.

We were fortunate to arrange the occasional field trip to a local First Nation powwow, or to celebrate important events in our work at a local Friendship Centre or within a community. Our teacher candidates served as volunteers at local Aboriginal Education conferences, and remained conscious of the principle of reciprocity by inviting local 
communities to share their cultures within the school community, and making the school community aware of local Aboriginal community events, such as celebrations, festivals, or historic sites.

Our teacher candidates learned to keep a current list of resources, which they shared with each other. For example, subsequent to volunteering at the Aboriginal Education Conference, they worked with a number of workshop presenters to create lesson plans. The workshop presenters provided their content and cultural expertise, and the teacher candidates added their understanding of lesson planning. This joining of resources and talents facilitated the creation of lesson plans that were meaningful and respectful.

As a guiding principle, teaching in context, using resources responsibly, allowed teacher candidates to gain a measure of confidence in implementing the Infusion. Knowing how to access and assess resources also provided teacher candidates with concrete ways to address their fear of not knowing.

\section{Move From Inclusion to Infusion}

Moving to and sustaining infusion required focused thinking on the part of teacher candidates. While it seemed straightforward to include a unit on First Nation, Métis, or Inuit traditions for social sciences, or study the art of West Coast First Nations in a unit on Canadian artists, the infusion of understandings on a day-to-day basis presented a greater challenge. Understanding that Aboriginal content should not been seen as an "add-on" to the curriculum, several teacher candidates shared ways they moved beyond inclusion to infusion.

One of our teacher candidates, who had been previously reluctant to self-identify, began to infuse traditional understandings into her teaching. She brought her drum to class and kept a rhythm as her primary students counted by twos, and incorporated beading into a math lesson on patterning. Another teacher candidate shared:

For procedural writing [Language Arts], I had the students watch a First Nations clip on the computer about games and had them write the procedure. I tried to pull Aboriginal content into different pieces, to pull little bits and pieces where I could. I could have done a procedural piece about tying shoelaces, but I thought First Nations games would be more interesting. (June 2010 Focus Group 1, Participant 5) 
Beyond the examples already discussed in this paper, the following are examples of what the Infusion "looked like" in local classrooms:

- Relating the classroom rules to the Seven Grandfather Teachings

- Developing understandings of traditions in the students' daily environment (e.g., the 2010 Canadian Olympics symbol)

- Studying Métis dot art during a math lesson on patterning

- Counting to drum beats in primary classes while discussing the traditions of drumming in local and global cultures

- Discussing First Nation, Métis, and Inuit concepts of conservation and environmentalism in relation to the school's eco-program

- Ensuring classroom libraries and reading baskets include Aboriginal authors and guided reading texts

- Using Aboriginal texts for shared reading (e.g., a dramatic read aloud of the poetry of Tekahionwake [E. Pauline Johnson])

- Promoting and reflecting on the origin of restorative justice models

- Modelling appropriate language and terminology (traditional regalia is not a costume)

- Inviting Elders into the classroom, in person or through web connections

- Comparing newspaper articles written about Aboriginal peoples and nonAboriginal peoples, asking how the author's perspective and/or description of the subject varied (for example, victims of violent crime)

- Increasing student awareness of environmental issues that impact traditional lands

- Going on community walks to consider whose footsteps have gone before in this place

- Ensuring that National Aboriginal Day is given recognition in the classroom and talk about how students can participate locally

- Exposing students to multiple art forms, including traditional dance, singing, musical instruments, painting, and sculpture

One of our former teacher candidates wrote to us about her experience of sustaining the work of the Infusion now that she is teaching full-time. She was reading the story Solomon's Tree by Andrea Spalding (2002) to her class to celebrate Aboriginal Day in 
her school. Several First Nation Elders and guests were in the school to support the teachers and students. She recounts:

Half way through the end of the story, two men came into the room and stood at the back. At the end of the story, I introduced myself and they introduced themselves to the class as volunteers for the day. They were both First Nations and one is an artist and the other makes masks for a living. The man who makes masks came up to me after I got the kids settled into their mask projects. He said, 'I was really nervous about coming today. I didn't think that this was the type of thing for me. I thought I'd feel really out of place and that I wouldn't enjoy myself. But you know what? I know I am meant to be here and that I am meant to be in your classroom today.' I said, 'Oh my goodness, that's so nice of you to say. Well I'm glad you feel that way and I'm so glad you are here, but what changed your mind?' He said, 'Well, the reason I know that I am meant to be here today is because I've heard that story before. I know it is a true story.' He then said, 'My father passed away and I miss him very much. He carved masks for a living and taught me the art of carving. Every time I carve a mask I feel my father's spirit in the tree I touch and mask I carve. He is with me and I know that he wanted me to be here today, because he is with me through that story you just read.' (Anonymous, personal communication, October 20, 2012)

This former teacher candidate's experience in her own classroom reinforces the importance of the Infusion and the potential that it brings to developing strong relationships and respectful understandings of First Nation, Métis, and Inuit traditions, perspectives, and histories for ALL children.

As a guiding principle, moving from inclusion to infusion provided our teacher candidates with concrete steps along a path on which each could move at a rate that suited his/her readiness.

It is our hope that what we have learned from our experiences will support others who choose to undertake an infusion of First Nation, Métis, and Inuit traditions, perspectives, and histories in their own classrooms. Neither the process nor the outcome has been perfect; however, we are focused on deepening our learning by examining the challenges we have faced. We are inspired to continue our work by listening to the stories of our teacher candidates who are taking the Infusion beyond our faculty and into the world. The work of the Infusion has just begun. 


\section{Acknowledgments}

We would like to thank our Aboriginal partners for generously sharing their knowledge and experience and providing ongoing guidance; the education team at the Barrie Site; and York University's Faculty of Education for supporting the Infusion.

\section{References}

Blimkie, M., Vetter, D., \& Haig-Brown, C. (2014). Shifting perspectives and practices: Teacher candidates' experiences of an Aboriginal infusion in mainstream teacher education. Brock Education, 23(2), 47-66.

Blimkie, M., Vetter, D., \& Stewart, C. (2011, May). Respecting ways of knowing: Culturallyresponsive assessment in a mainstream teacher education program. Paper presented at the Ministry of Education/Faculties of Education Forum, OISE/UT, Toronto, Ontario, Canada.

Bruner, J. (1966). Toward a theory of instruction. Cambridge, MA: Harvard University Press.

Bruner, J. (2003). Making stories: Law, literature, life. Cambridge, MA: Harvard University Press.

Dion, S. (2007). Disrupting molded images: Identities, responsibilities and relationshipsTeachers and Indigenous subject material. Teaching Education, 18, 329-342.

Elementary Teachers' Federation of Ontario. (1999). We're erasing prejudice for good: Resource Guide. Toronto, ON: Elementary Teachers' Federation of Ontario.

Freire, P. (1974). Education for critical consciousness. New York: Continuum Books.

Haig-Brown, C. (2008). Not-a-course outline: First Nation, Métis, and Inuit infusion (university course syllabus). Barrie, ON: Faculty of Education, York University.

King, T. (2003). The truth about stories: A native narrative. Toronto, ON: House of Anansi Press.
Kulchyski, P. (2005). Like the sound of a drum: Aboriginal cultural politics in Denendeh and Nunavut. Winnipeg, MB: University of Manitoba Press.

McGregor, L. (2008/2010). Circle of life evaluation worksheet. Barrie, ON: Author.

Meuse-Dallien, T. (2003). The sharing circle: Stories about First Nations culture. Halifax, NS: Nimbus.

Saul, J.R. (2009). A fair country: Telling truths about Canada. Toronto, ON: Viking Press

Simcoe Catholic District School Board. (2008). Aboriginal perspectives: The teacher's toolkit. Retrieved from: http://www.smcdsb.on.ca/ UserFiles/Servers/Server_6/File/Board\%20 Office $\% 20$ Files/Employees/Aboriginal\%20 Education/Elementary/Grade\%201/Gr01_ Lang_Circle_Eng.pdf

Simcoe Muskoka Catholic District School Board. (2009). Making good tracks: Community members speak. Barrie, ON: Author.

Spalding, A. (2002). Solomon's tree. Victoria, BC: Orca Book.

Stevens, M. (2009, April). Unpublished education assignment for the Bachelor of Education Program, York University, Barrie, Ontario, Canada.

Style, E. (1996). Curriculum as window and mirror. National S.E.E.D. project. Retrieved from: http://www.library.wisc.edu/edvrc/docs/ public/pdfs/SEEDReadings/Curriculum Window.pdf 
Vetter, D., \& Blimkie, M. (2011). Learning to teach in a culturally meaningful and respectful way: The first steps in creating a First Nation, Métis, and Inuit education infusion in a mainstream teacher education program. Canadian Journal of Native Studies, 31(2), 173-185.
Wells, C. G., \& Chang-Wells, G. L. (1992). Constructing knowledge together: Classrooms as centers of inquiry and literacy. Portsmouth, $\mathrm{NH}$ : Heineman.

Wilder, L. (1935/1994). Little house on the prairie. New York: Harper Collins.

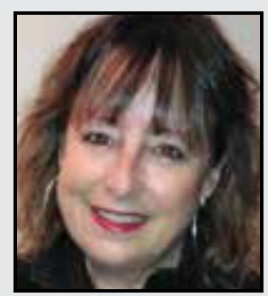

Diane Vetter is the Practicum Coordinator for the York University Faculty of Education. She holds a PhD in Education from York with research interests in teacher education, and oral language and learning. She served as Barrie Site Lead in the Consecutive Teacher Education Program, with a focus on the Infusion of First Nation, Métis, and Inuit traditions, perspectives, and histories across the curriculum. Dr. Vetter has published on the topics of oral language, inclusive learning, and crosscurricular infusion.

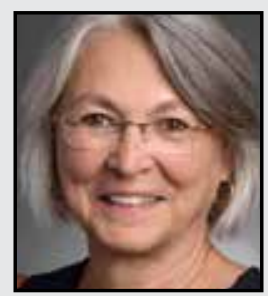

Celia Haig-Brown is the Associate Dean Research \& Professional Development at York University Faculty of Education. She holds a PhD from the University of British Columbia. Her scholarly interests include (de)colonizing research and practice; critical ethnography; critical/feminist pedagogy; learning from the land; adult \& community education; curriculum development; and ways of knowing. Dr. Haig-Brown has published on the topics of Indigenous thought, appropriation and Non-Aboriginal people, pedagogy of the land, and First Nations education. 


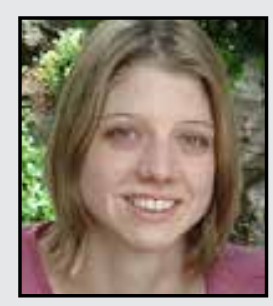

Melissa Blimkie is completing her PhD at York University's Faculty of Education. She holds a Master of Education degree from Queen's University. Her research interests include Indigenous education, land-based pedagogies, oral history, and community sustainability. Ms. Blimkie has taught undergraduate and graduate courses on pedagogy of the land and issues in Indigenous education. She has published on the topics of pedagogy of the land and cross-curricular infusion of First Nation, Métis, and Inuit traditions, perspectives, and histories. 